\title{
Assessment of Radiation Dose to Eyes Lens from CT of the Head and Trunk
}

\author{
AbDulraheEm A. Kinsara, PhD, and Mohammed Ali M. Al Haban, PhD, \\ Department of Nuclear Engineering, Faculty of Engineering, \\ King Abdulaziz University, Jeddah, Saudi Arabia
}

\begin{abstract}
Radiation exposure of the patient during Computerized Axial Tomography examinations is known to be relatively high. Limited knowledge is available on doses received indirectly by organs, during diagnostic procedures. In the present study, the radiation dose to the lens of the eyes was measured from various Computerized Axial Tomography protocols for head and trunk imaging. Thermoluminescence dosimeters were used to measure organ doses in an anthropomorphic Rando Alderson phantom. The unwanted (non-useful) radiation doses delivered to the eye lens during Computerized Axial Tomography examination of head, facial bone, orbits, abdomen, chest, pelvis, neck, nasopharynx, cervical spine, lumbar spine, and sacroiliac joint were assessed. The following results are obtained: head scans, mean value $8.74 \mathrm{mGy}$; facial bone scans, mean value $8.03 \mathrm{mGy}$; orbital scans, mean value 61.51 mGy; abdomen scans, mean value $0.76 \mathrm{mGy}$; chest scans, mean value 1.03 mGy; pelvis scans, mean value $0.46 \mathrm{mGy}$; neck scans, mean value $1.81 \mathrm{mGy}$; nasopharynx scans, mean value $8.56 \mathrm{mGy}$; cervical spine scans, mean value $6.15 \mathrm{mGy}$; lumber spine scans, mean value $0.46 \mathrm{mGy}$; and sacroiliac joint scans, mean value $0.35 \mathrm{mGy}$. The doses received by the eye lens from Computerized Axial Tomography examinations and general rediogaphy examinations are compared. It is observed that relatively high doses of unwanted radiations are delivered to the eye lens from Computerized Axial Tomography examinations.
\end{abstract}

Keywords: Radiation dose, Eye lens, Phantom, Computerized axial tomography, Thermoluminescence dosimeters

\section{Introduction}

Computerized Axial Tomography (CAT) offers a high diagnostic capability due to

Correspondence \& reprint requests to: Dr. Abdulraheem A. Kinsara

P.O. Box 80204, Jeddah 21589, Saudi Arabia

Accepted for publication: 25 May 2003. Received: 09 September 2001 
three-dimensional visualization of an organ. The use of CAT has grown rapidly despite the fact that the radiation dose associated with it; is relatively higher to other types of radiological investigations ${ }^{[1]}$. Limited knowledge is available on doses received by organs, indirectly during diagnostic procedures. For estimating the related radiation risk, the assessment of the dose of individual organs, resulting from CAT examinations, is necessary. Decisions for making CAT examinations were found, in most cases, to be carried out without proper knowledge of the radiation doses received by the patient. In CAT of the brain, the lens of the eye were of concern as cataract formation is welldocumented result of radiation damage ${ }^{[2,3]}$. Irradiation can cause lens opacification. The effect is believed to be deterministic, with a threshold of between 0.5 and 2 Gy for detectable opacities. Visual impairment due to contract occurs with exposures over 5 $\mathrm{Gy}^{[4]}$. CAT scanning protocol influences patient doses ${ }^{[5]}$. Changes in the plane scanning by use of different gantry angulations can affect the radiation dose to the lens of the eye ${ }^{[6]}$. Dose awareness is becoming increasingly important for both referring physicians and radiologists in determining indications and deciding which types of imaging procedures and specific protocols should be used.

The purpose of this study was to measure the dose to the eye lens from various CAT protocols for head and trunk imaging using Thermoluminescent dosimeters (TLDs) applied to a phantom. The results are compared with values from different authors available in literature.

\section{Materials and Methods}

Direct measurement of the absorbed dose in relevant organs was performed with Thermoluminescence dosimeters (TLDs) employing an anthropomorphic (Rando Alderson) phantom. Absorbed doses were measured during routine CAT examinations of head and trunk using a GE 9800 CAT scanner machine of third generation available at King Fahad Specialist Hospital (KFSH) in Al Qassim. Technical parameters of the selected protocols are summarized in Table 1. The anatomical reference planes are tabulated in Table 2. General Electric (GE) Medical System Group in Riyadh did the calibration of CAT scanner GE 9800.

TABLE 1. CAT exposure data for eleven CAT examinations.

\begin{tabular}{|l|c|c|c|c|c|c|c|c|}
\hline Examination & $\mathrm{kV}$ & $\mathrm{mA}$ & $\begin{array}{c}\text { Scan Time } \\
(\mathrm{sec})\end{array}$ & $\begin{array}{c}\text { Slice Thickness } \\
(\mathrm{mm})\end{array}$ & $\begin{array}{c}\text { No. of slices } \\
(\mathrm{avg})\end{array}$ & $\begin{array}{c}\text { SFOV } \\
(\mathrm{mm})\end{array}$ & $\begin{array}{c}\text { Tilting } \\
(\mathrm{deg} .)\end{array}$ & $\begin{array}{c}\text { Start-end } \\
\text { point }\end{array}$ \\
\hline Head & 120 & 170 & 2 & $5.0-10.0$ & 16 & 250 & $20+$ & $\mathrm{N}-1$ to N-2 \\
\hline F. Bone & 120 & 170 & 2 & 5.0 & 19 & 250 & 0 & $\mathrm{~N}-3$ to N-4 \\
\hline Orbits(axial) & 120 & 170 & 2 & 3.0 & 19 & 250 & 0 & $\mathrm{~N}-5$ to N-6 \\
\hline Nasoph. & 120 & 170 & 2 & 5.0 & 19 & 230 & 0 & $\mathrm{~N}-15$ to N-16 \\
\hline Abdomen & 120 & 170 & 2 & 10.0 & 19 & 340 & 0 & N-7 to N-8 \\
\hline Chest & 120 & 170 & 2 & 10.0 & 24 & 340 & 0 & N-9 to N-10 \\
\hline Pelvis & 120 & 170 & 2 & 5.0 & 24 & 340 & 0 & N-11 to N-12 \\
\hline Neck & 120 & 170 & 2 & 1.5 & 35 & 190 & 0 & N-13 to N-14 \\
\hline C. spine & 120 & 170 & 2 & 3.0 & 46 & 180 & 0 & N-17 to N-18 \\
\hline L. spine & 120 & 170 & 2 & 5.0 & 16 & 180 & 0 & N-19 to N-20 \\
\hline S. I. joint & 120 & 170 & 2 & 5.0 & 28 & 250 & 0 & N-21 to N-22 \\
\hline
\end{tabular}


TABLE 2. Selected anatomical reference planes.

\begin{tabular}{|c|c|}
\hline Abbreviation & Anatomical reference plane \\
\hline $\mathrm{N}-1$ & Base of skull \\
\hline $\mathrm{N}-2$ & Vertex of skull \\
\hline $\mathrm{N}-3$ & Top of frontal sinuses \\
\hline $\mathrm{N}-4$ & Bottom of the mandible \\
\hline $\mathrm{N}-5$ & Infra orbital margin \\
\hline $\mathrm{N}-6$ & Supra orbital margin \\
\hline $\mathrm{N}-7$ & Dome of the diaphragm \\
\hline $\mathrm{N}-8$ & Lumber spine (5), L5 \\
\hline $\mathrm{N}-9$ & Lung apices \\
\hline $\mathrm{N}-10$ & Bottom of the lungs \\
\hline $\mathrm{N}-11$ & Iliac crest \\
\hline $\mathrm{N}-12$ & Pubic symphysis \\
\hline $\mathrm{N}-13$ & Angle jaw \\
\hline $\mathrm{N}-14$ & Sternal notch \\
\hline $\mathrm{N}-15$ & Hyoid bone \\
\hline $\mathrm{N}-16$ & Cervical spine (1), C1 (disc only) \\
\hline $\mathrm{N}-17$ & Cervical spine (7), C7 (disc only) \\
\hline $\mathrm{N}-18$ & Lumber spine (1), L1 (disc only) \\
\hline $\mathrm{N}-19$ & Lumber spine (5), L5 (disc only) \\
\hline $\mathrm{N}-20$ & Anterior superior iliac spine (L5-S1discs) \\
\hline $\mathrm{N}-21$ & Anterior inferior iliac spine \\
\hline $\mathrm{N}-22$ & Lower limb of sacrum \\
\hline
\end{tabular}

To determine the average, unwanted, (non-useful) radiation dose to the organs using reference man phantom, we had to know the location of the specific organs of interest in the body. To define standard values of level and ranges of specific organs with respect to anatomical fixed points, we followed the procedure described by Mini et al. ${ }^{[7]}$ and the slice number of the sectional reference man phantom labeled by Alderson Research Laboratories ${ }^{[8-10]}$. For eye lens, the TLDs were place $10 \mathrm{~mm}$ behind the anterior surface of the globe in the equatorial plane ${ }^{[8-10]}$. The sites of the TLD's in the reference man sectional phantom used were slicing number 3 for the eye lens (Fig. 1).

The calibration was done using ${ }^{137} \mathrm{Cs}$ source of strength $90 \mathrm{Ci}$. The TLD reader used in this study was Harshow TLD system 4000.

For the purpose of this study, unwanted (non-useful) radiation doses delivered to the organs of interest during standard CAT examinations of the head and trunk, including CAT of head, facial bone, orbits, abdomen, chest, pelvis, neck, nasopharynx, cervical spine, lumbar spine, and sacroiliac joint were assessed.

To make a good comparison of the received doses from CAT examinations and plain radiography, the reference man phantom was exposed to a general X-ray machine as a real patient for head, facial bone, orbits, abdomen, chest, pelvis, cervical spine, lumbar spine, and sacroiliac joints radiography. TLDs were positioned inside the organs of interest in the same locations as were in CAT examinations. 


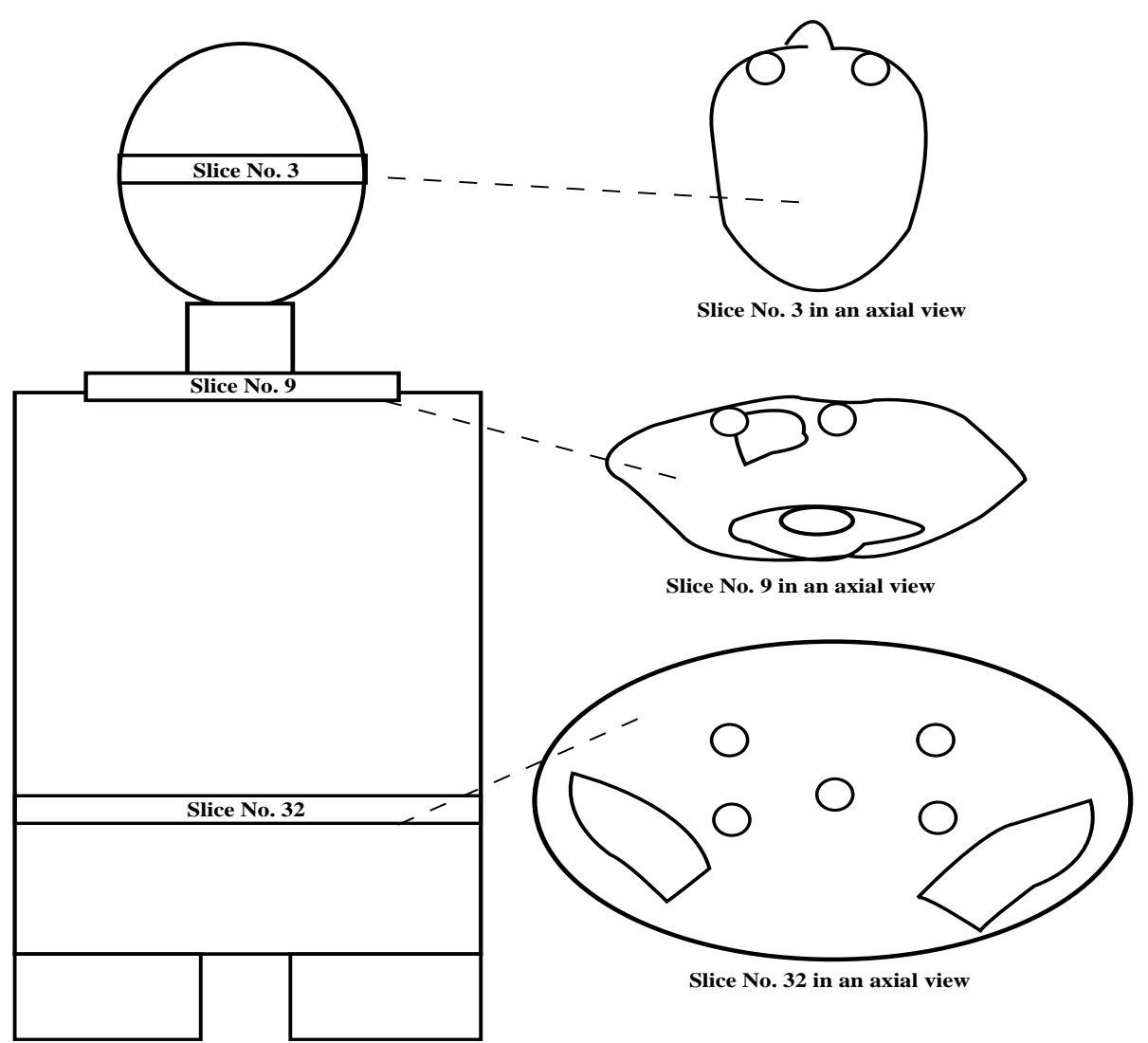

Fig. 1. Positions of the TLDs inside reference man phantom.

Slice No. 3 represents selected position of eye lens.

Slice No. 9 represents elected position of the thyroid gland.

Slice No. 32 represents selected position of the ovaries.

Adjacent diagram shows the selected positions in an axial

view showing TLD holes.

The TLDs used in the present study were LiF TLD-100. These were taken from the same batch and were annealed under the conditions. The reading of TLDs were taken under the same reading parameters using the same TLD reader.

The manufacturing company (GE Medical System) was responsible for regular monthly maintenance of the CAT scanner. The same company was requested to ensure that the pre-set parameters were in actual positions during the time of irradiations of the phantom by CT scanner.

\section{Results and Discussions}

\section{(a) Head CAT Examination}

Since most of the patients referred to the Radiology Department of KFSH were for head CAT examinations, we measured the eye lens dose from each scan, starting from 
the base of skull ending with the vertex of the head. For head CAT examination, the position of the TLD was changed when the irradiation of each slice was completed. This was done to show the relation between the eye lens dose and incremental distance when Supra Orbital Metal (SOM) baseline was selected to be the plane of scan. The results for the eye lens dose measured from each irradiated slice are given in Table 3, while the cumulative doses for the eye lenses were detected after CAT examination procedures had been completed. The average doses were found to be $8.52 \pm 0.8 \mathrm{mGy}$ and $8.96 \pm 0.7 \mathrm{mGy}$ to the right and left eye lens, respectively. These are given in Table 4. In this present study, the mean value of the eye lens dose for head CAT scan was $8.74 \pm 0.53 \mathrm{mGy}$ as unwanted (non-useful) irradiation which is similar to the reported value of 3-10 mGy for head scan using an EMI 1010 and Somatome DR2 scanner ${ }^{[11]}$.

TABLE 3. The results of the eye lens doses measured from each scan of head CAT scan with $120 \mathrm{kV}$ and $140 \mathrm{~mA}$.

\begin{tabular}{|c|c|c|c|c|c|}
\hline Slice No. & $\begin{array}{l}\text { Slice Width } \\
(\mathrm{mm})\end{array}$ & $\begin{array}{c}\text { Table } \\
\text { Increment } \\
(\mathrm{mm})\end{array}$ & $\begin{array}{l}\text { Scanning } \\
\text { Time } \\
(\mathrm{sec})\end{array}$ & $\begin{array}{l}\text { Left Eye } \\
\text { Lens Dose } \\
\text { (mGy) }\end{array}$ & $\begin{array}{l}\text { Right Eye } \\
\text { Lens Dose } \\
\text { (mGy) }\end{array}$ \\
\hline 1 & 5 & 5 & 2 & 2.81 & \\
\hline 2 & 5 & 5 & 2 & & 2.60 \\
\hline 3 & 5 & 5 & 2 & 2.22 & \\
\hline 4 & 5 & 5 & 2 & & 1.74 \\
\hline 5 & 5 & 5 & 2 & 1.60 & \\
\hline 6 & 5 & 5 & 2 & & 1.50 \\
\hline 7 & 5 & 5 & 2 & 1.46 & \\
\hline 8 & 10 & 10 & 2 & & 1.22 \\
\hline 9 & 10 & 10 & 2 & 1.16 & \\
\hline 10 & 10 & 10 & 2 & & 1.10 \\
\hline 11 & 10 & 10 & 2 & 1.00 & \\
\hline 12 & 10 & 10 & 2 & & 0.84 \\
\hline 13 & 10 & 10 & 2 & 0.62 & \\
\hline 14 & 10 & 10 & 2 & & 0.58 \\
\hline 15 & 10 & 10 & 2 & 0.52 & \\
\hline 16 & 10 & 10 & 2 & & 0.43 \\
\hline 17 & 10 & 10 & 2 & 0.40 & \\
\hline
\end{tabular}

\section{(b) Facial Bone CAT Examination}

The average doses received by the eye lenses from facial bone CAT examination were found to be $(8.17 \pm 0.24) \mathrm{mGy}$ to the right eye lens and $(7.9 \pm 0.27) \mathrm{mGy}$ to the left eye lens (Table 4). The mean value of the eye lens dose from facial bone CAT was $(8.03 \pm 0.18) \mathrm{mGy}$. This value is in agreement with value of $9.0 \mathrm{mGy}$ as reported by the National Radiological Protection Board (NRPB), U.K. ${ }^{[12]}$.

\section{(c) Orbits CAT Examination}

The average doses received by the eye lenses from orbits CAT examinations were measured to be $(59.73 \pm 3.8) \mathrm{mGy}$ to the right eye lens and $(63.30 \pm 4.6) \mathrm{mGy}$ to the left eye lens (Table 4). The mean value of eye lens dose in this present study was found to be $(61.51 \pm 2.98) \mathrm{mGy}$ which is comparable with the published value of 68 mGy obtained with EMI CT 1010 scanner $^{[12]}$. 


\section{(d) Abdomen CAT Examination}

The results of radiation doses to the eye lens from abdominal CAT examinations were found to be $(0.70 \pm 0.24) \mathrm{mGy}$ to the right eye lens and $(0.82 \pm 0.26) \mathrm{mGy}$ to the left eye lens. The mean value of eye lens dose from abdomen CAT examination was found to be $(0.76 \pm 0.18) \mathrm{mGy}$ which is higher than the published value of Mini et al. ${ }^{[7]}$ where they used different protocols for CAT examination.

\section{(e) Chest CAT Examination}

The results of eye lens dose from chest CAT examination were found to be $(0.96 \pm$ $0.05) \mathrm{mGy}$ to the right lens and $(1.1 \pm 0.09) \mathrm{mGy}$ to the left eye lens. These are given in Table 4. Mini et al. ${ }^{[7]}$ used the following protocol to measure the eye lens dose from chest CAT examination: $120 \mathrm{kV}$ generator voltage, $150 \mathrm{mAs}, 10 \mathrm{~mm}$ slice thickness, $10-15 \mathrm{~mm}$ table increment, and the total number of slices 35. The TLDs were positioned $8-10 \mathrm{~mm}$ above the lens on the surface of the skin. The mean dose to the eye lens from this measurement was $0.37 \mathrm{mGy}$.

In the present study, the eye lens dose received from chest CAT examination was $(1.03 \pm 0.45) \mathrm{mGy}$ as unwanted (non-useful) irradiation, which is higher than the dose estimated by Mini et al. ${ }^{[7]}$. This difference can be accounted for the use of different scanning protocols in this present study.

\section{(f) Pelvis CAT Examination}

In pelvic CAT examination, organs of the lower part of the trunk received the highest doses of radiation including the ovaries, and, on the other hand, the doses to the thyroid, eye lens are low. In the present study, the doses to the right and left eye lens were found to be $(0.53 \pm 0.05) \mathrm{mGy}$ and $(0.38 \pm 0.04) \mathrm{mGy}$, respectively; and a mean dose of $(0.46 \pm 0.03)$ to the eye lens. The present value is higher than the published values $[7,12]$.

\section{(g) Neck CAT Examination}

The results of the received doses to the eye lens from neck CAT examinations were found to be $(1.78 \pm 0.12) \mathrm{mGy}$ to the right eye lens and $(1.84 \pm 0.18) \mathrm{mGy}$ to the left eye lens. The mean value of the eye lens dose from neck CAT examination was (1.81 \pm 0.11 ) $\mathrm{mGy}$ as unwanted (non-useful) irradiation with the following protocol: $120 \mathrm{kV}$, $170 \mathrm{~mA}, 2 \mathrm{sec}$ exposure time, $.5 \mathrm{~mm}$ slice width, $5 \mathrm{~mm}$ table increment, and unenhanced scan. The NRPB surveyed 75 scanners using straight gantry to scan the phantom ${ }^{[12]}$; and the mean value of the eye lens dose from neck CAT examination was $0.62 \mathrm{mGy}$. It is likely that the present value of high dose is due to the use of different radiographic protocols.

\section{(h) Nasopharynx CAT Examination}

The results of the cumulative doses were found to be $(8.45 \pm 0.90) \mathrm{mGy}$ to the right eye lens and $(8.67 \pm 0.50) \mathrm{mGy}$ to the left eye lens from CAT scans of nasophrynx. The present value of mean dose to the eye lenses was $(8.56 \pm 0.51) \mathrm{mGy}$ as unwanted 
(non-useful) irradiation and this was much higher than the dose $4.81 \mathrm{mGy}$ as obtained by the NRPB survey ${ }^{[12]}$. This difference may be accounted for the use of different techniques and different scanners in the present study.

\section{(i) Cervical Spine CAT Examination}

The results of the average doses to eye lenses from this examination were found to be $(6.0 \pm 0.50)$ to the right eye lens and $(6.3 \pm 0.6) \mathrm{mGy}$ to the left eye lens with mean value of $(6.15 \pm 0.39) \mathrm{mGy}$ as unwanted (non-useful) irradiation for the eye lens. The present value is higher than the corresponding value published in the NRPB survey report $^{[12]}$.

\section{(j) Lumber Spine CAT Examination}

The average doses from lumber spine CAT examinations were found to be: $(0.43 \pm$ $0.10) \mathrm{mGy}$ to the right eye lens and $(0.50 \pm 0.10) \mathrm{mGy}$ to the left eye lens. The mean value of our finding was $(0.46 \pm 0.07) \mathrm{mGy}$, as unwanted (non-useful) irradiation dose of the eye lens. The dose of the eye lens was low as expected due to the long distance between the primary beams region and the eye lens.

\section{(k) Sacroiliac Joint CAT Examination}

The results of the measured dose from sacroiliac joint were found to be: $(0.34 \pm$ $0.02) \mathrm{mGy}$ to the right eye lens and $(0.35 \pm 0.01) \mathrm{mGy}$ to the left eye lens. The dose to the eye lens from sacroiliac joint examination was $(0.35 \pm 0.01)$ mGy as unwanted (non-useful) irradiation. No result was found in the literature to compare with our result.

TABLE 4. Cumulative doses of the eye lens from different CAT examinations with $120 \mathrm{kV}$ and $170 \mathrm{~mA}$.

\begin{tabular}{|c|c|c|c|c|c|c|c|}
\hline \multirow{2}{*}{$\begin{array}{l}\text { Type of CAT } \\
\text { Examination }\end{array}$} & \multirow{2}{*}{$\begin{array}{l}\text { Slice } \\
\text { Width } \\
(\mathrm{mm})\end{array}$} & \multirow{2}{*}{$\begin{array}{c}\text { Table } \\
\text { Increment } \\
(\mathrm{mm})\end{array}$} & \multirow{2}{*}{$\begin{array}{l}\text { Scan } \\
\text { Time } \\
(\mathrm{sec})\end{array}$} & \multirow{2}{*}{$\begin{array}{l}\text { No. of } \\
\text { Slices }\end{array}$} & \multicolumn{2}{|c|}{$\begin{array}{l}\text { Eye lens dose } \\
\text { (mGy) }\end{array}$} & \multirow{2}{*}{$\begin{array}{l}\text { Mean value } \\
\text { of eye lens } \\
\text { dose (mGy) }\end{array}$} \\
\hline & & & & & Right & Left & \\
\hline Head & $5-10$ & $5-10$ & 2 & 19 & $8.52 \pm 0.80$ & $8.96 \pm 0.70$ & $8.74 \pm 0.53$ \\
\hline Bone Facial & 5 & 5 & 2 & 19 & $8.17 \pm 0.24$ & $7.90 \pm 0.27$ & $8.03 \pm 0.18$ \\
\hline Orbits & 3 & 3 & 2 & 19 & $59.73 \pm 3.80$ & $63.30 \pm 4.60$ & $61.51 \pm 2.98$ \\
\hline Abdomen & 10 & 10 & 2 & 24 & $0.70 \pm 0.24$ & $0.82 \pm 0.26$ & $0.76 \pm 0.18$ \\
\hline Chest & 10 & 10 & 2 & 29 & $0.96 \pm 0.05$ & $1.1 \pm 0.09$ & $1.03 \pm 0.05$ \\
\hline Pelvis & 5 & 5 & 2 & 28 & $0.38 \pm 0.04$ & $0.53 \pm 0.05$ & $0.46 \pm 0.03$ \\
\hline Neck & 5 & 5 & 2 & 24 & $1.78 \pm 0.12$ & $1.84 \pm 0.18$ & $1.81 \pm 0.11$ \\
\hline Nasopharynx & 5 & 5 & 2 & 19 & $8.45 \pm 0.90$ & $8.67 \pm 0.50$ & $8.56 \pm 0.51$ \\
\hline Cerical Spine & 1.5 & 1.5 & 2 & 35 & $6.00 \pm 0.50$ & $6.30 \pm 0.60$ & $6.15 \pm 0.39$ \\
\hline Lumber Spine & 3 & 3 & 2 & 46 & $0.43 \pm 0.10$ & $0.50 \pm 0.10$ & $0.46 \pm 0.07$ \\
\hline Sacroiliac Joint & 5 & 5 & 2 & 16 & $0.34 \pm 0.02$ & $0.35 \pm 0.01$ & $0.35 \pm 0.01$ \\
\hline
\end{tabular}

The eye lens doses in $\mathrm{mGy}$ received during X-ray CAT examinations of eleven regions of the head and trunk are shown in Figure 2. The results of the dose to the eye lens received during CAT examinations of various organs showed that there was a 


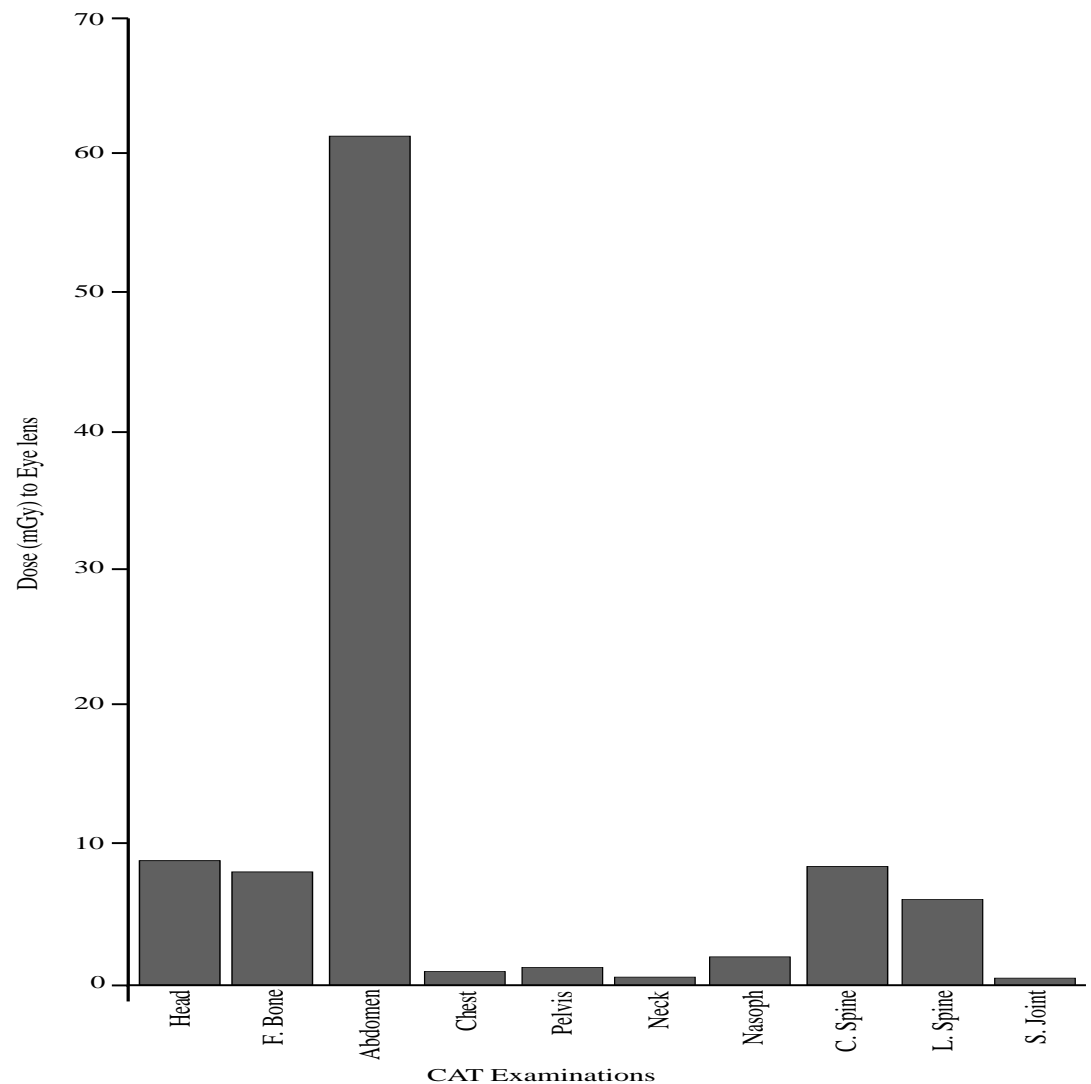

Fig. 2. Eye lens doses received during CAT examiniations of eleven regions of the head and truck.

TABLE 5. CAT doses and their equivalent doses from plain chest X-ray with (114 kVp, $12.5 \mathrm{mAs}$, and 180 $\mathrm{cm}$ FFD) of reference phantom used in this study.

\begin{tabular}{|l|c|c|}
\hline \multirow{2}{*}{\multicolumn{1}{c|}{ CAT Examination }} & \multicolumn{2}{|c|}{ Eye lens dose (mGy) } \\
\cline { 2 - 3 } & $\begin{array}{c}\text { Delivered dose from } \\
\text { CAT Examinations }\end{array}$ & $\begin{array}{c}\text { Equivalent No. of } \\
\text { Chest X-Ray }\end{array}$ \\
\hline Head & $8.74 \pm 0.53$ & 633 \\
\hline Facial Bone (axial) & $8.03 \pm 0.18$ & 621 \\
\hline Orbits (axial) & $61.51 \pm 2.98$ & 5,076 \\
\hline Abdomen & $0.76 \pm 0.18$ & 79 \\
\hline Chest & $1.03 \pm 0.45$ & 35 \\
\hline Pelvis & $0.46 \pm 0.03$ & 139 \\
\hline Neck & $1.81 \pm 0.11$ & 669 \\
\hline Nasopharynx & $8.56 \pm 0.51$ & 472 \\
\hline Cerical Spine & $6.15 \pm 0.39$ & 35 \\
\hline Lumber Spine & $0.46 \pm 0.05$ & 27 \\
\hline Sacroiliac Joint & $0.35 \pm 0.01$ & 79 \\
\hline
\end{tabular}


marked variation in organ or tissue dose depending on the protocol used, techniques applied, mode of the CAT examinations and exposure setting of each examination. Compared with general radiography examinations, relatively high doses of unwanted radiation were delivered with Computed Axial Tomography (CAT). This is shown in Table 5. The measurement was performed for the eye lens from general radiography examinations.

Thus, in view of the potentially high patient doses, CAT examinations should only be carried out after there has been proper clinical justification for the examination of each individual patient by an experienced radiologist. Examinations on children require a higher level of justification, since such patients are at greater risk from radiation than adults.

\section{References}

[1] Royal College of Radiologist and the National Radiological Protection Board. Patients dose reduction in diagnostic radiology, Vol. 1, Chilton, England: National Radiological Protection Board; 1997.

[2] Merriam GR, Focht EF. A clinical study of radiation cataracts and the relationship to dose. AJR 1957; 77: 759-785.

[3] Cogan DG, Donaldson DD, Reese ABE. Clinical and pathological characteristics of radiation cataract. Arch Opthalmol 1952; 47: 55-70.

[4] MacLennan AC, Hadley DM. Radiation dose to the lens from computed tomography scanning in a neuroradiology department. Br J Radiol 1995; 68(805): 19-22.

[5] Geleijns J, Van Unnik JG, Zoetelief J, Zweers D, Broerse JJ. Comparison of two methods for assessing patient dose from computed tomography. Br J Radiol 1994; 67(796): 360-365.

[6] Lund E, Halaburt H. Irradiation dose to the lens of the eye during CT of the head. Neuroradiology 1982; 22(4): 181-184.

[7] Mini RL, Vock P, Mury R, Schneeberger PP. Radiation exposure of patients who undergo CT of the trunk. Radiology 1995; 195(2): 557-562.

[8] MacLennan AC. Radiation dose to the lens from coronal CT scanning of the sinuses. Clin Radiol 1995; 50(4): 265-267.

[9] Shrimpton PC, Wall BF, Fisher ES. The tissue-equivalence of the Alderson Rando anthropomorphic phantom for X-rays of diagnostic qualities. Phys Med Biol 1981; 26(1): 133-139.

[10] Huda W, Sandison GA. Estimation of mean organ doses in diagnostic radiology from Rando phantom measurements. Health Phys 1984; 47(3): 463-467.

[11] Mostrom U, Ytterbergh C, Bergstrom K. Eye lens dose in cranial computed tomography with reference to the technical development of CT scanners. Acta Radiol Diagn 1986; 27(5): 599-606.

[12] Shrimpton PC, Jones DG, Hillier MC. Survey of CT practice in the UK. National Radiological Protection Board (NRPB), U.K., Report. Vol. 13, No. 4, 1992. 


\section{تقييم الجرعة الإشعاعية لأجزاء من الجمسم في الفحوصات القياسية

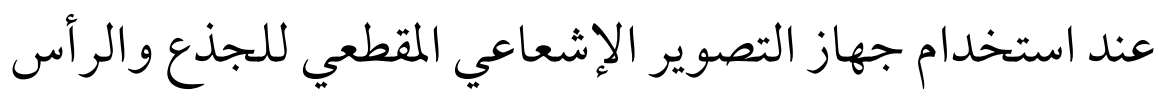

عبدالرحيم كنسارة و محمد علي الهبدان

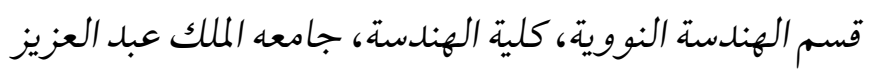
جسـدة - المملكة العربية السعودية

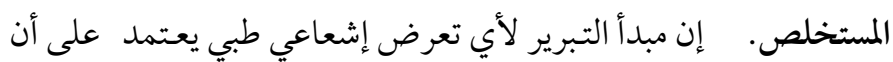

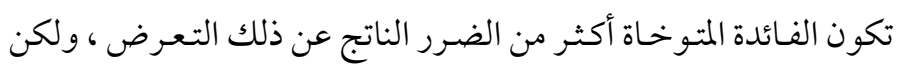

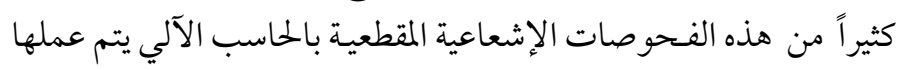

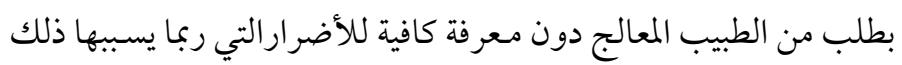

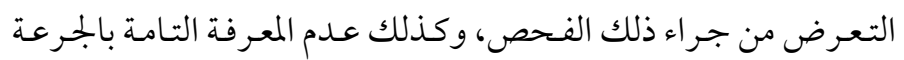

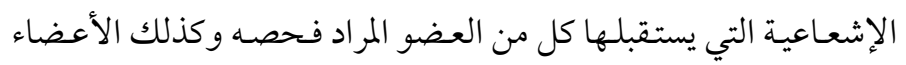

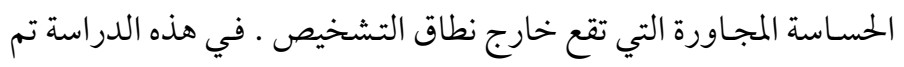

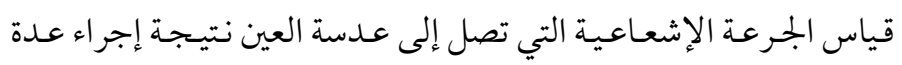

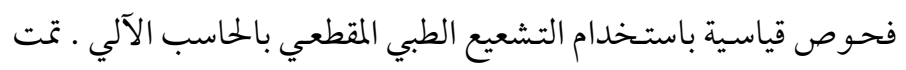

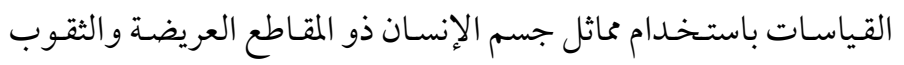

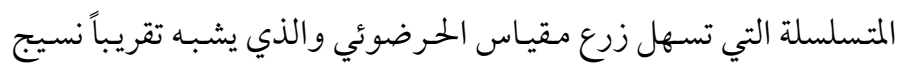

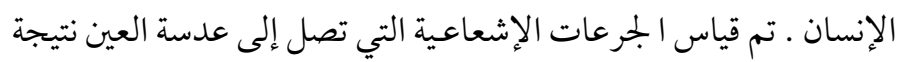

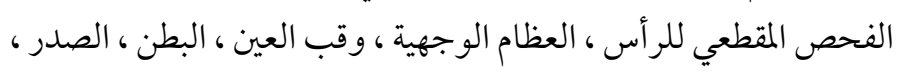

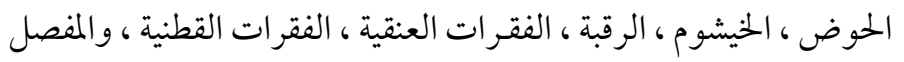

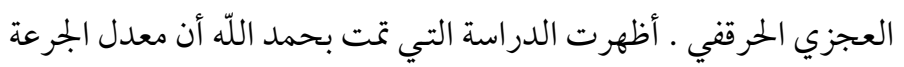

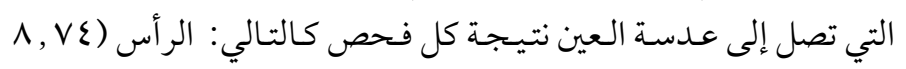

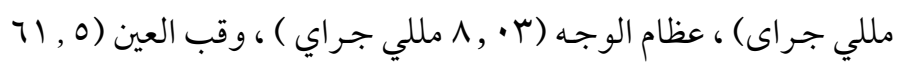

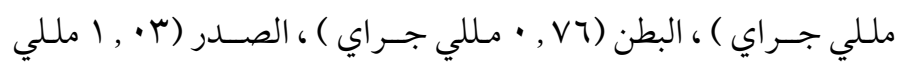

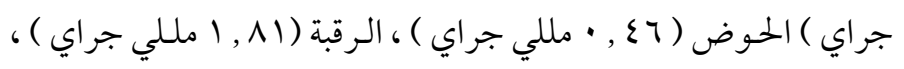

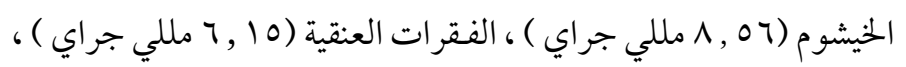


الفقرات القطنية (7 ع , · مللي جـراي ) ، و المفصل العجـزي الحـرقفي

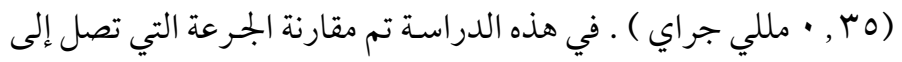

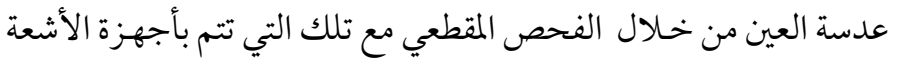

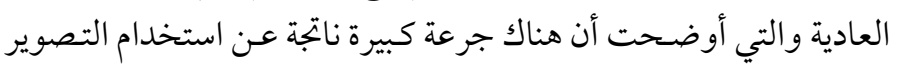
الإشعاعي المقطعي. 